\title{
Knowledge and public health practices during lockdown towards COVID-19 in Bangladesh
}

\author{
Sharmin Akhtar1, Rubel Ahmed ${ }^{2}$, Sharmin Jahan, Md. Mosharaf Hossain ${ }^{4}$ \\ ${ }^{1,4}$ Faculty of Business, Economics and Social Development, University Malaysia Terengganu, Terengganu, Malaysia \\ ${ }^{2}$ Global Public Health Research Foundation, Uttara, Dhaka, Bangladesh \\ ${ }^{3}$ Department of Food Safety and Quality Engineering, University of Debrecen, Hungary
}

\begin{tabular}{l} 
Article Info \\
\hline Article history: \\
Received Jun 8, 2021 \\
Revised Aug 18, 2021 \\
Accepted Aug 25, 2021 \\
\hline
\end{tabular}

\section{Keywords:}

Bangladesh

COVID-19

Knowledge

Lockdown

Public awareness and practices

\begin{abstract}
The study aimed to assess the role of having knowledge and essential hygiene practices to prevent coronavirus pandemic and to find out the relationship between people's knowledge and good hygiene practices with socio-demographic variables during coronavirus disease 2019 (COVID-19) pandemic situation. In this study, data were collected from 248 respondents for cross-sectional study using voluntary response sampling from April, 30 2020 to May, 30 2020, during lockdown situation in Bangladesh. Descriptive statistics were done to calculate the frequencies and percentages by using Stata SE 14.2 (StataCorp). Chi-square was performed at the significance level of $5 \%$ to find the factors which were associated with knowledge about COVID-19. After knowing about COVID-19, 86.29\% respondents had taken preventive measures and $71.37 \%$ respondents had agreed to stay at home. Among the respondents, $47.98 \%$ were involved in services and were positively associated with good general knowledge of preventive practices. Our present findings indicated significant relationship between good general knowledge and practice of general people towards COVID-19 outbreak in Bangladesh. The findings of the study are helpful for the researchers and the population to follow all good promotional practices for preventive measures against coronavirus.
\end{abstract}

This is an open access article under the CC BY-SA license.



\section{Corresponding Author:}

Md. Mosharaf Hossain

Faculty of Business

Economics and Social Development

University Malaysia Terengganu

Terengganu, Malaysia

Email: md.hossain@umt.edu.my

\section{INTRODUCTION}

Being a developing country, the health system of Bangladesh is not good enough to tackle coronavirus disease 2019 (COVID-19) pandemic. In this situation awareness, keeping good knowledge and safety health practices are the only way to survive. In China, the confirmed cases of coronavirus were first found in 2019 [1], [2] and the case related death was reported in 2020 [3]. A few weeks later, coronavirus infection spread over the globe in rapidly [4]. The disease was announced as global concern of health emergency on 30 January, 2020 [5]. World Health Organization (WHO) declared a new disease called as COVID-19 on 11 February 2020 [6], which was later declared as global pandemic [7], [8] when about 114 countries and areas were affected by this disease [9], [10].

The world people were initiated awareness of healthcare for the country peoples towards coronavirus due to similarity with severe acute respiratory syndrome (SARS) virus [8]. In general people of 
different countries have a lot of facts regarding prevention and management of COVID-19 outbreaks [11]. In Bangladesh, the number of confirmed cases and total deaths reached to 989,219 and 15792 respectively on July 8, 2021 [12]. Most of the COVID-19 infected countries have put in place lockdowns and public health measures to promote the physical distancing, hand washing with soap, sanitizing, isolating cases, testing and tracing contacts of people with coronavirus infection [5]. A large number of employees in different types of organizations are working from home to avoid physical transmission. On 16 March 2020, all types of educational institutions have been closed for uncertainty in Bangladesh [13], [14]. Since onset of coronavirus pandemic, proper use of hand gloves, masks, sanitizers and face shields have increased exponentially along with its prices in local market [15]. The higher authorities of the countries are warning the public to avoid any types of gatherings to prevent the transmission and infection in the healthy population [16]. Despite these warning and concerning efforts, many people of different countries are ignoring social distancing due to attitudinal problems and religious matter [17]. Another previous study stated that a number of sociodemographic factors (age and gender) can affect the spread of coronavirus [18].

Regarding the knowledge and practices of coronavirus, several studies showed mediocre level of knowledge and practices among the general population [19]-[21] including young students [21]-[23] and slum dwellers [24]. All these studies have assessed the level of knowledge and practice for general perspectives. For example, in 2020, Ferdous et al. [19] evaluate the level of knowledge about how the coronavirus affected and transmitted by the general population [19], [25]. Those studies are not properly and solely assessed the knowledge and awareness of the coronavirus subject to the preventive behavioral aspects. At this second wave, familiarity and basic level of knowledge is not sufficient to reduce the impact and translate into the preventive behavior. Results of this study can be translated into the practices of the general population by considering their knowledge subject to the preventive measures. Besides, results on preventive behaviors such as hand washing, social distancing is useful for implementing the national level of strategies for reducing the impact of coronavirus. Bangladesh is a heavily populated country with inadequate health-care resources; without public participation, controlling COVID-19 will be impossible. Data on public awareness and prevention behaviors about COVID-19 is required. This will relieve the government of some of the burden of fighting outbreak strategies. There have been a few researches undertaken in the country that deal with this topic. Therefore, the present study was aimed to assess the role of having knowledge and essential hygiene practices to prevent coronavirus pandemic. Moreover, we have tried to find out the relationship between people's knowledge and good hygiene practices with socio-demographic variables during COVID-19 pandemic situation.

\section{RESEARCH METHOD}

\subsection{Materials}

In the present investigation, an online survey was conducted from April, 302020 to May, 302020. Respondents were selected using a voluntary response sampling method. Respondents with internet access were recruited for this online survey. Dhaka, Rajshahi, Chittagong, Khulna, Mymensingh, Sylhet, Rangpur, Barisal division and immigrant population of Bangladesh were considered as respondents for the study. Selected study population from all nine regions comprised of educated/non-educated respondents. Total 248 responses were recorded and used as raw materials.

\subsection{Questionnaire and data collection}

A questionnaire was developed on Google forms, considering the important factors, knowledge and general people attitude during the COVID-19 pandemic, in Bangladesh. The questionnaire was sent randomly to the population through messenger, e-mail, and Facebook. For data collection, questionnaire and its contents were designed by moderated Pérez-Fuentes et al. method [26]. The questionnaire was arranged in different parts including, socio-demographic approaches (five items), and source of information (two items), knowledge and practices for prevention of coronavirus (seven items). Unlimited time was given to respondents to read, comprehend evaluate and answer all the survey questions. Respondent's identity and personal information was maintained confidentially throughout the study and the data was only used for research purposes.

\subsection{Data analysis}

Data analyses were performed by Pérez-Fuentes et al. [27] method. Responses were recorded in Microsoft Excel and transformed to Stata for further analysis. Descriptive statistics were done to calculate the frequencies and percentages by using Stata SE 14.2 (Stata corp.). The analysis of chi-square was performed at the significance level of 5\% to find the factors which were associated with knowledge about COVID-19. The score of knowledge was arranged from 0 to 15, respondents who scored 15, 10-14 and less than 10 points were considered to have good general knowledge, medium knowledge and poor knowledge towards coronavirus respectively. 


\subsection{Ethical clearance}

This study was approved by the Institute of Biological Sciences Research Ethics Committee, University of Rajshahi, Bangladesh and the approval no. was deposited (Ref. no. B.0003/BS.03.02.2020).

\section{RESULTS AND DISCUSSION}

\subsection{Socio demographic characteristics}

More than $30 \%$ of the respondents were 26-35 years' age group. The non-educated respondents who could access internet in this study were also observed. Among the respondents, $45.56 \%$ were females, $54.03 \%$ were males and $0.40 \%$ preferred not to answer. Of all, $79.84 \%$ respondents had higher education, proportion of $9.27 \%$ completed secondary education, $5.65 \%$ primary and $5.24 \%$ were non-educated. In this study, largest proportion of respondent was involved in jobs $(47.98 \%), 27.82 \%$ were students, $12.10 \%$ of the respondents were housewife, $8.87 \%$ respondents were involved in business and $3.23 \%$ were retired population. More than $38 \%$ of respondents were from Dhaka division. The socio demographic characteristics of the respondents were represented in Table 1.

Table 1. Demographic characteristics of the respondents

\begin{tabular}{cccc}
\hline Item & Category & Frequency $(\mathrm{n})$ & Percent $(\%)$ \\
\hline \multirow{4}{*}{ Age group (years) } & $18-25$ & 56 & 22.58 \\
& $26-35$ & 84 & 33.87 \\
& $36-45$ & 57 & 22.98 \\
Gender & $46-60$ & 38 & 15.32 \\
& Above 60 & 13 & 5.24 \\
Educational qualification & Female & 113 & 45.56 \\
& Male & 134 & 54.03 \\
& Not to answer & 1 & 0.40 \\
& Higher education & 198 & 79.84 \\
& Secondary & 23 & 9.27 \\
& Primary & 14 & 5.65 \\
& Non-educated & 13 & 5.24 \\
& Service & 119 & 47.98 \\
& Student & 69 & 27.82 \\
& Housewife & 30 & 12.10 \\
& Business & 22 & 8.87 \\
& Retired & 8 & 3.23 \\
& Dhaka & 96 & 38.71 \\
& Rajshahi & 80 & 32.26 \\
& Chittagong & 52 & 20.97 \\
& Khulna & 4 & 1.61 \\
& Mymensingh & 3 & 1.21 \\
& Sylhet & 3 & 1.21 \\
& Rangpur & 3 & 1.21 \\
& Barisal & 3 & 1.21 \\
& Immigrant & 4 & 1.61 \\
\hline & & &
\end{tabular}

\subsection{Awareness and hygiene practices about preventive measures}

The majority with $86.29 \%$ respondents had heard about the disease. On the other hands, only $5.24 \%$ of respondents had known about two weeks of quarantine period and $6.85 \%$ had no idea about quarantine period. This indicates that there is a lack of quarantine knowledge among the Bangladeshi people compared with the Jordanian population [28]. The practices for using mask and maintained handkerchief or tissue or elbow when sneezing/cough was found among $87.50 \%$ of all respondents. In addition, almost $87 \%$ respondents had maintained social distance or avoided social ceremony and $82.66 \%$ respondent's children were abandoned to go out for outdoor activities during lockdown. Moreover, more than $71 \%$ of the respondents had awareness about stay at home for preventing coronavirus disease but $22.98 \%$ were confused about these preventive measures. Only $5.65 \%$ responded that stay at home policy cannot control coronavirus disease. Percentage distribution of awareness and hygiene practices were presented in Table 2. 
Table 2. Percentage distribution of awareness and hygiene practices about preventive measures of respondents on COVID-19

\begin{tabular}{|c|c|c|c|c|}
\hline Item & Questionnaire & Category & Frequency (n) & $\begin{array}{c}\text { Percent } \\
(\%)\end{array}$ \\
\hline \multirow{2}{*}{ Preventive measures } & Do you take preventive steps after knowing about & No & 34 & 13.71 \\
\hline & COVID-19? & Yes & 214 & 86.29 \\
\hline \multirow{3}{*}{$\begin{array}{l}\text { Understanding about } \\
\text { quarantine period }\end{array}$} & \multirow{3}{*}{ What do you mean about the quarantine period? } & 1 week & 12 & 4.84 \\
\hline & & 1 month & 206 & 83.06 \\
\hline & & No idea & 17 & 6.85 \\
\hline \multirow{2}{*}{$\begin{array}{l}\text { Using mask when go } \\
\text { outside }\end{array}$} & \multirow{2}{*}{$\begin{array}{l}\text { Does all members of your family use mask when go } \\
\text { outside? }\end{array}$} & Sometimes & 9 & 3.63 \\
\hline & & Yes & 217 & 87.50 \\
\hline \multirow{2}{*}{$\begin{array}{l}\text { Using handkerchief or } \\
\text { tissue or elbow }\end{array}$} & \multirow{2}{*}{$\begin{array}{l}\text { Do you cover your mouth using handkerchief or tissue } \\
\text { or elbow when you cough or sneeze? }\end{array}$} & No & 31 & 12.50 \\
\hline & & Yes & 217 & 87.50 \\
\hline $\begin{array}{l}\text { Give permission children } \\
\text { to go outside }\end{array}$ & Do you give permission your children to go outside? & Yes & 18 & 7.26 \\
\hline \multirow{3}{*}{ Stay at home } & \multirow{3}{*}{$\begin{array}{l}\text { Do you think that stay at home can help control } \\
\text { COVID-19? }\end{array}$} & No & 14 & 5.65 \\
\hline & & May be & 57 & 22.98 \\
\hline & & Yes & 177 & 71.37 \\
\hline
\end{tabular}

\subsection{Association of knowledge and socio-demographic characteristics}

Table 3 indicates that the respondents who were higher educated and involved in service were significantly associated with good knowledge practices towards COVID-19. Moreover, respondents were of 26-35 years' age group had significant general knowledge $(\mathrm{p}<0.05)$. On the other hand, respondents who were above 60 years old and non-educated had poor knowledge about prevention of hygiene practices. However, our study shown more than $52 \%$ respondents who were from Dhaka division of Bangladesh had good general knowledge on maintaining safety practices. Previous studies also found that increasing level of educational qualification and middle age of the people has more knowledge on the coronavirus transmission and prevention measures [19], [20]. In this COVID-19 condition, people with higher degrees or education are more likely to have greater knowledge and preventive behaviour [19], [20], which is consistent with the current findings. However, the current study found that having more knowledge about COVID-19 increased the number of COVID-19 preventive activities.

Table 3. Effects of different socio-demographic characteristics vs general knowledge of respondents on

\begin{tabular}{|c|c|c|c|c|c|c|}
\hline \multicolumn{7}{|c|}{ COVID-19 } \\
\hline Item & Category & $\mathrm{Pk}(\%)$ & $\mathrm{Mk}(\%)$ & $\mathrm{Gk}(\%)$ & Chi-square & p-value \\
\hline \multirow{4}{*}{ Educational qualification } & Non educated & 76.92 & 15.38 & 7.69 & & \\
\hline & Primary & 35.71 & 35.71 & 28.57 & & \\
\hline & Secondary & 8.70 & 60.87 & 30.43 & 131.482 & 0.000 \\
\hline & Higher education & 0.51 & 37.37 & 62.12 & & \\
\hline \multirow[t]{9}{*}{ Age group (years) } & Above 60 & 30.77 & 53.85 & 15.38 & & \\
\hline & $46-60$ & 15.79 & 42.11 & 42.11 & & \\
\hline & $36-45$ & 7.02 & 35.09 & 57.89 & 25.054 & 0.002 \\
\hline & $26-35$ & 2.38 & 34.52 & 63.10 & & \\
\hline & $18-25$ & 3.57 & 41.07 & 55.36 & & \\
\hline & Service & 1.68 & 35.29 & 63.03 & & \\
\hline & Student & 1.45 & 37.68 & 60.87 & & \\
\hline & Housewife & 33.33 & 40.00 & 26.67 & 52.653 & 0.000 \\
\hline & Business & 13.64 & 45.45 & 40.91 & & \\
\hline \multirow[t]{9}{*}{ Occupation } & Retired & 25.00 & 62.50 & 12.50 & & \\
\hline & Dhaka & 5.21 & 42.71 & 52.08 & & \\
\hline & Rajshahi & 16.25 & 37.50 & 46.25 & & \\
\hline & Chittagong & 0 & 28.85 & 71.15 & & \\
\hline & Khulna & 0 & 25.00 & 75.00 & & \\
\hline & Mymensingh & 0 & 33.33 & 66.67 & 26.844 & 0.043 \\
\hline & Sylhet & 0 & 33.33 & 66.67 & & \\
\hline & Rangpur & 0 & 33.33 & 66.67 & & \\
\hline & Barisal & 0 & 100.00 & 0 & & \\
\hline Area of residence & Immigrant & 0 & 25.00 & 75.00 & & \\
\hline
\end{tabular}

NB. Pk= Poor knowledge, Mk= Medium knowledge, $\mathrm{Gk}=$ Good knowledge, $-=0.00 \%$ 


\subsection{Devices at home and sources of collecting information about COVID-19}

Maximum respondents (48.79\%) had got the information about coronavirus from internet. However, about $43 \%$ respondents had accessed to television, $8.065 \%$ and $0.4032 \%$ of the respondents accessed to newspaper and radio respectively at their home as shown in Figure 1. Furthermore, majority of the respondent's (35.89\%) received updates from television, $31.85 \%$ of the respondent's sources were YouTube and Facebook, 23.39\% respondents used mobile to talk with their relevant sources for knowing coronavirus information and some of them used newspaper for updated information as shown in Figure 2. One study in Satkhira district found that social and mass media were the common sources of information and majority of them can get the information from the social media who have access to the internet. Both medium of sources of information can reduces the misinterpretation of the pandemic [29].

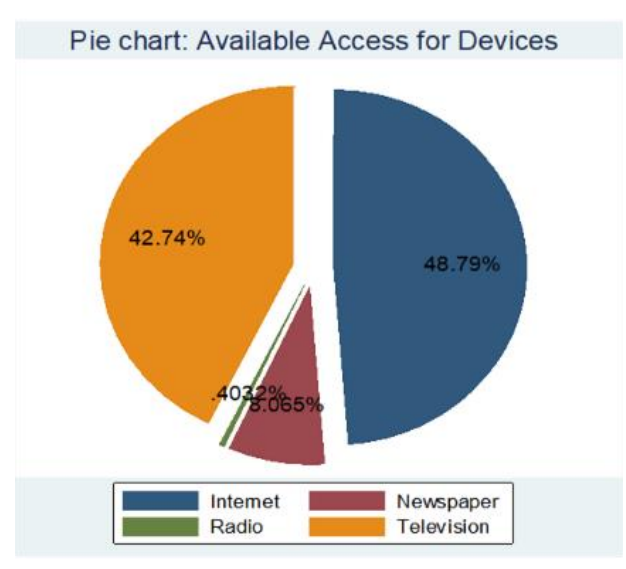

Figure 1. The rate $(\%)$ of access for devices

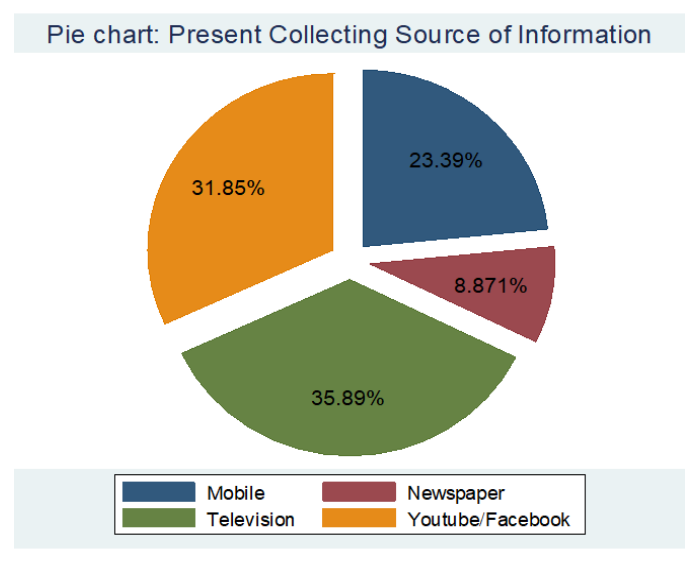

Figure 2. Percentage of sources of COVID-19 information

\subsection{Hand washing practices}

The highest proportion of respondents who washed their hands 7-10 times on a daily basis was $50.4 \%$ followed by $22.58 \%$ respondents who washed hands 3-6 times in a day. On the other hand, the lowest proportion of respondents washing their hands 15-20 times in a day was $7.258 \%$ while $19.76 \%$ respondents only washed their hands 10-15 times in a day as shown in Figure 3. Evidence suggested that the rate of washing hand increased significantly $(88.4 \%)$ after the coronavirus invasion and on average they wash their hands three times per day [30]-[32]. Some study also found that by using the nationwide representative data, more than $3 / 4$ people wash their hand after coming back from outsides [30], [33]. But after sneezing, coughing the rate of washing hand is comparatively low (about 37\%) [30].

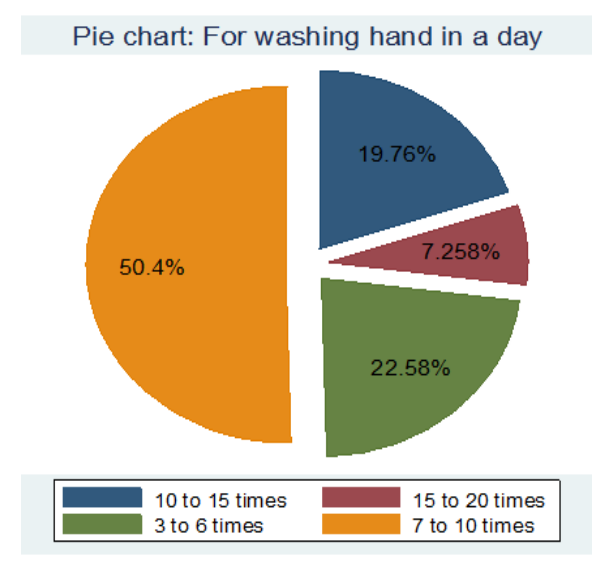

Figure 3. The ratio (\%) of hand washing practices on daily basis 


\subsection{Maintaining social distance by occupation and staying at home by respondents' age group}

The highest proportions of respondents were from service group who maintained social distancing about $48 \%$. Besides this, almost $28 \%$ students followed social distancing prevention steps and the lowest proportion of retired respondents kept social distancing only 3\% as shown in Figure 4 (a). On the other hand, 26-35 years' age group respondents who stayed at home to control the pandemic situation were higher than other age group of the respondents as shown in Figure 4 (b).

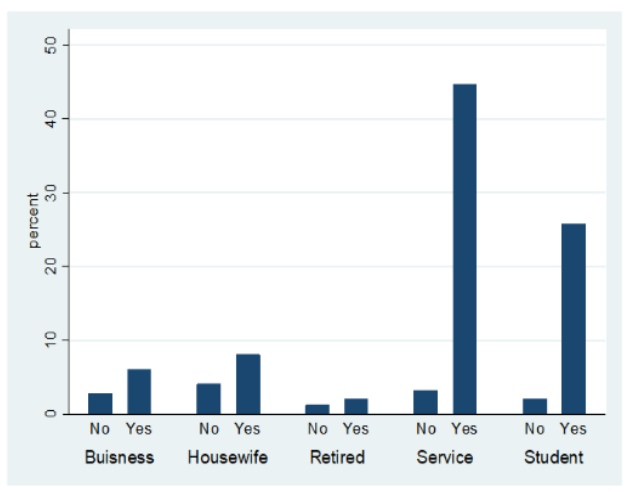

(a)



(b)

Figure 4. (a) Distance by occupation; (b) Staying at home practices by age group

Nowadays, COVID-19 is the major concern of health and economic sectors for all over the world. This study was performed to evaluate knowledge and practices in daily life to adapt publicly in the period of global pandemic. The study was aimed to acquire more information on association of knowledge and sociodemographic variables of Bangladeshi population. A similar investigation was conducted previous outbreak during the period of 2014 which showed similarity with COVID-19 [34]. Previous study reported about Ebola outbreak knowledge, attitude, and perception of Ebola virus infection [35]. Having optimistic attitudes and appropriate practices would be surely associated with good knowledge for encouraging and maintaining safe practices regarding COVID-19 outbreak [36].

In the present study, we found that respondents who were higher educated either graduate or post graduate were showed good practices of knowledge to confirm better health prevention measures. Most respondents in our study were involved in the service and 26-35 years' age group had good general knowledge and practiced regarding coronavirus issue. A recent study shown the majority of slum dwellers have inadequate knowledge and poor practices of COVID-19 in Bangladesh [24]. The use of masks, hand washing and social distancing are the effective sets of the preventive measures to stop transmission of coronavirus from people to people [37], which support our present findings. In case of Indian population, one study showed that about $85 \%$ respondents practiced hand washing procedures, $37 \%$ agreed for using masks to prevent the transmission of COVID-19 [11]. Another researcher also stated about $95 \%$ respondents have maintained safety procedures, washed hand normally, stay at home and keeping physical distance to stop the transmission of coronavirus in Nepal [38]. The WHO also suggested to washing with soap and or alcohol based rub to protect people from coronavirus infection [4]. Another study observed that $89.5 \%$ and $53.8 \%$ university going students have the practice of washing hands frequently and using face masks properly while going out in public places respectively to avoid coronavirus infection [22]. This results support our present findings. The previous study exposed that gender, age group, marital status, higher education and occupations were positively associated with lower level of knowledge in Chinese residents [36]. Whitelaw et al. [39] reported that people were used to depend on digital machineries for epidemic prevention and reaction, observation, surveillance, interaction, isolation and medical treatment.

Immigrant populations have significantly good knowledge of coronavirus than that of other divisional parts of the country. The People's Republic of Bangladesh has so far acted to raise awareness through news, press release, and social media [40]. But, the government may be unable to control circumstances. So, general public participation, political leader and supporters, industrials, business man, pharmaceutical companies, garment owners, medical practitioner and international supports are required on a quick basis to overcome smoothly [38], [41]-[43]. Therefore, we need to take necessary steps for maintaining knowledge and awareness practices for healthy life during lockdown in Bangladeshi community. Further, sustainable measurement to overcome the COVID-19 difficulties could be build-up by appropriate practices of the residences. 


\section{CONCLUSION}

This study concluded that the respondents have good manure, positive thinking ability and practices to safe themselves from the COVID-19 outbreak. Higher education has significant association with knowledge and good practices towards COVID-19 outbreak in Bangladesh. Moreover, most of the higher educated respondents showed positive thoughts and proper health practices. These findings are helpful for the researchers and the population to follow all good promotional practices for preventive measures against coronavirus.

\section{ACKNOWLEDGEMENTS}

The authors would like to express their sincere gratitude to all the participants who give their valuable time for providing information during the present study.

\section{REFERENCES}

[1] M.L. Holshue et al., "First case of 2019 Novel Coronavirus in the United States," N. Engl. J. Med., vol. 382, no. 10, pp. 929-936, 2020, doi: 10.1056/NEJMoa2001191.

[2] H. Lu, C. W. Stratton, and Y.-W. Tang, "Outbreak of pneumonia of unknown etiology in Wuhan, China: The mystery and the miracle," J. Med. Virol., vol. 92, no. 4, pp. 401-402, 2020, doi: 10.1002/jmv.25678.

[3] L.-L. Ren et al., "Identification of a novel coronavirus causing severe pneumonia in human: a descriptive study," Chin. Med. J. (Engl)., vol. 133, no. 9, pp. 1015-1024, 2020, doi: 10.1097/CM9.0000000000000722.

[4] WHO. "Rolling Updates on Coronavirus Disease (COVID-19)," 2020, [Online]. Available: https://www.who.int/emergencies/diseases/novel-coronavirus-2019/events-as-they-happen

[5] WHO. "Coronavirus Disease 2019 (COVID 19) Situation Report-149," 2020. [Online]. Available: https://www.who.int/docs/default-source/coronaviruse/situation-reports/20200617-COVID-19-sitrep-149.pdf? sfvrsn=3b3137b0_4.

[6] H. A. Rothan and S. N. Byrareddy, "The epidemiology and pathogenesis of coronavirus disease (COVID-19) outbreak," J. Autoimmun., vol. 109, 2020, doi: 10.1016/j.jaut.2020.102433.

[7] Y. Bai et al., "Presumed Asymptomatic Carrier Transmission of COVID-19," JAMA, vol. 323, no. 14, pp. 14061407, 2020, doi: 10.1001/jama.2020.2565.

[8] J. H. Yoo, "The Fight against the 2019-nCoV Outbreak: an Arduous March Has Just Begun," Journal of Korean Medical Science, vol. 35, no. 4, 2020, doi: 10.3346/jkms.2020.35.e56.

[9] C. Huang et al., "Clinical features of patients infected with 2019 novel coronavirus in Wuhan, China," Lancet, vol. 395, no. 10223, pp. 497-506, 2020, doi: 10.1016/S0140-6736(20)30183-5.

[10] S. T. Ali et al., "Serial interval of SARS-CoV-2 was shortened over time by nonpharmaceutical interventions," Science (80-.), vol. 369, no. 6507, pp. 1106 LP - 1109, 2020, doi: 10.1126/science.abc9004.

[11] D. Roy, S. Tripathy, S. K. Kar, N. Sharma, S. K. Verma, and V. Kaushal, "Study of knowledge, attitude, anxiety \& perceived mental healthcare need in Indian population during COVID-19 pandemic," Asian J. Psychiatr., vol. 51, 2020, doi: 10.1016/j.ajp.2020.102083.

[12] World Health Organization "World health organization: Bangladesh situation," 2021, [Online] Available: https://covid19.who.int/region/searo/country/bd.

[13] K.A. Ahmed, "Dhaka Tribune daily newspaper, Bangladesh," 2020, [Online] Available: https://www.dhakatribune.com/bangladesh/dhaka/2020/03/16/govt-directs-shutting-all-educational-institutionsmach-17-to-31.

[14] Akhtar et al., "Association between knowledge and depression at rising time of COVID 19 in Bangladesh," Int. J. Public Health Sci., vol. 10, no. 2, pp. 387-393, 2021, doi: 10.11591/ijphs.v10i2.20642

[15] S. Feng, C. Shen, N. Xia, W. Song, M. Fan, and B. J. Cowling, "Rational use of face masks in the COVID-19 pandemic," Lancet. Respir. Med., vol. 8, no. 5, pp. 434-436, 2020, doi: 10.1016/S2213-2600(20)30134-X.

[16] B. McCloskey et al., "Mass gathering events and reducing further global spread of COVID-19: a political and public health dilemma," Lancet (London, England), vol. 395, no. 10230, pp. 1096-1099, 2020, doi: 10.1016/S0140-6736(20)30681-4.

[17] The Tribune India: Letters to the editor", Tribuneindia.com, 2021. [Online]. Available: https://www.tribuneindia.com/news/opinion/letters? monthYear=March\%202020. [Accessed: 10- Mar- 2021].

[18] M. U. G. Kraemer et al., "The effect of human mobility and control measures on the COVID-19 epidemic in China," Science, vol. 368, no. 6490, pp. 493 LP - 497, 2020, doi: 10.1126/science.abb4218

[19] M.Z. Ferdous, M.S. Islam, M.T. Sikder, A.S.M. Mosaddek, J.A. Zegarra-Valdivia, and D. Gozal, "Knowledge, attitude, and practice regarding COVID-19 outbreak in Bangladesh: An online-based cross-sectional study," PloS one, vol. 15, no. 10, pp. e0239254, 2020.

[20] A. Rahman and N.J. Sathi, "Knowledge, Attitude, and Preventive Practices toward COVID-19 among Bangladeshi Internet Users," Electronic Journal of General Medicine, vol. 17, no. 5, pp. 2-6, 2020, doi: 10.29333/ejgm/8223

[21] M.M. Rahman, J.M. Jhinuk, N.H. Nabila, M.T. Yeasmin, I.A. Shobuj, T.H. Sayma, and S.H. Shah, "Knowledge, attitude, and practices towards COVID-19 during the rapid rise period: a cross-sectional survey among public university students of Bangladesh," SciMedicine Journal, vol. 3, no. 2, pp. 116-128, 2021, doi: 10.1371/journal.pone.023925. 
[22] M.A. Wadood, A.S.M.A. Mamun, M. Rafi, M. K. Islam, S. Mohd, L.L. Lee, and M.G. Hossain, "Knowledge, attitude, practice and perception regarding COVID-19 among students in Bangladesh: Survey in Rajshahi University," Medrxiv, 2020, doi: 10.1101/2020.04.21.20074757.

[23] R. Banik, M. Rahman, M.T. Sikder, Q.M. Rahman, and M.U.R. Pranta, "Knowledge, attitudes, and practices related to the COVID-19 pandemic among Bangladeshi youth: a web-based cross-sectional analysis," Journal of Public Health, vol. 1, no. 11, pp. 1-15, 2021, doi: 10.21203/rs.3.rs-37946/v1.

[24] S. Islam, G.I. Emran, E. Rahman, R. Banik, T. Sikder, L. Smith, and S. Hossain, "Knowledge, attitudes and practices associated with the COVID-19 among slum dwellers resided in Dhaka City: a Bangladeshi interviewbased survey," Journal of Public Health, vol. 43, no.1, pp. 13-25, 2021, doi: 10.1093/pubmed/fdaa182.

[25] T.L. P. Agusti, N. Arkhaesi, A. Riansari, R. Hapsari, "Knowledge, attitudes, and practices of Indonesian medical and non-medical undergraduate students toward COVID-19," International Journal of Public Health Science (IJPHS), vol. 10, no. 4, 2021.

[26] M. Pérez-Fuentes et al., "Questionnaire on Perception of Threat from COVID-19," Journal of Clinical Medicine, vol. 9, no. 4, p. 1196, 2020, doi: 10.3390/jcm9041196.

[27] M. Pérez-Fuentes, I. Herera-Peco, M. Molero Jurado, N. Oropesa Ruiz, D. Ayuso-Murillo, and J. Gázquez Linares, "The Development and Validation of the Healthcare Professional Humanization Scale (HUMAS) for Nursing," International Journal of Environmental Research and Public Health, vol. 16, no. 20, 2019, doi: 10.3390/ijerph16203999.

[28] M. Al-Hussami, M. El-Hneiti, A.B. Salameh, L.A. Sharour, and R. Al-Hussami, "Knowledge, Attitudes, and Behavior Toward COVID-19 Among Jordanian Residents During the Quarantine Period of the COVID-19 Pandemic: A National Survey," Disaster Medicine and Public Health Preparedness, vol. 9, no. 4, pp.1-9, 2021, doi: 10.1017/dmp.2021.34.

[29] M. Bakebillah, M.A. Billah, B.L. Wubishet, and M.N. Khan, "Community level misconception about COVID-19 and its associated factors: Evidence from a cross-sectional study in Bangladesh," medRxiv, 2021.

[30] A. Sayeed et al., "Handwashing with soap: A concern for overuse of water amidst the COVID-19 pandemic in Bangladesh," Groundwater for Sustainable Development, vol. 13, p. 100561, 2021. Available: 10.1016/j.gsd.2021.100561.

[31] A.K. Amegah, "Improving handwashing habits and household air quality in Africa after COVID-19," The Lancet Global Health, vol. 8, no. 9, pp. e1110-e1111, 2020, doi: 10.1016/S2214-109X(20)30353-3.

[32] R. Roshan, A.S. Feroz, Z. Rafique, and N. Virani, "Rigorous hand hygiene practices among health care workers reduce hospital-associated infections during the COVID-19 pandemic," Journal of Primary Care \& Community Health, vol. 11, no. 7, pp. 345-50, 2020, doi: 10.1177/2150132720943331.

[33] S. Kundu, A. Sayeed, M.H. Al Banna, M.R. Begum, T. Kormoker, K. Brazendale, and M.S. Khan, "Knowledge, attitudes, and practices towards measures for prevention of the spread of COVID-19: An online cross-sectional survey among Bangladeshi residents," MexRxiv, 2021.

[34] T. B. Abebe et al., "Healthcare professionals' awareness, knowledge, attitudes, perceptions and beliefs about Ebola at Gondar University Hospital, Northwest Ethiopia: a cross-sectional study," J. Public Health Africa, vol. 7, no. 2, pp. 55-60, 2016, doi: 10.4081/jphia.2016.570.

[35] O. Ilesanmi and F. O. Alele, "Knowledge, attitude and perception of Ebola virus disease among secondary school students in Ondo State, Nigeria, October, 2014," PLoS Curr., vol. 8, no. 1, pp. 1-11, 2016, doi: 10.1371/currents.outbreaks.c04b88cd5cd03cccb99e125657eecd76.

[36] B.-L. Zhong et al., "Knowledge, attitudes, and practices towards COVID-19 among Chinese residents during the rapid rise period of the COVID-19 outbreak: a quick online cross-sectional survey," Int. J. Biol. Sci., vol. 16, no. 10, pp. 1745-1752, 2020, doi: 10.7150/ijbs.45221.

[37] WHO, "Advice on the use of masks in the context of COVID-19: interim guidance, 5 June 2020," World Health Organization, 2020.

[38] D. R. Singh, D. R. Sunuwar, K. Karki, S. Ghimire, and N. Shrestha, "Knowledge and perception towards universal safety precautions during early phase of the COVID-19 outbreak in Nepal," J. Community Health, vol. 45, pp. 1116-1122, 2020.

[39] S. Whitelaw, M. A. Mamas, E. Topol, and H. G. C. Van Spall, "Applications of digital technology in COVID-19 pandemic planning and response," Lancet Digit. Heal., vol. 2, no. 8, pp. 435-440, 2020, doi: 10.1016/S2589$7500(20) 30142-4$.

[40] S. Anwar, M. Nasrullah, and M. J. Hosen, "COVID-19 and Bangladesh: Challenges and how to address them," Front. Public Heal., vol. 8, pp. 1-8, doi: 10.3389/fpubh.2020.00154, 2020.

[41] M. Begum, M. S. Farid, M. J. Alam, and S. Barua, "COVID-19 and Bangladesh: socio-economic analysis towards the future correspondence," Asian J. Agric. Extension, Econ. Sociol., vol. 38, no. 9, pp. 143-155, 2020, doi: 10.9734/ajaees/2020/v38i930417.

[42] M. Hossain, K.K.C. Mani, M.S. Sherina, K.S. Hayati, and M.R. Islam, "Knowledge and Awareness about STDs among the Women in Bangladesh," BMC Public Health, vol. 14, no. 775, pp. 1-7, 2014, doi: 10.1186/1471-245814-775.

[43] M.M. Hossain, R.M. Min, Z. Muhammad, and K.K.C. Mani, "Effectiveness of Mobile SMS based Counselling Intervention in Improving Knowledge, Attitude and Practices of HIV/AIDS Patients enrolled in Hospitals/NGOs in Terengganu, Malaysia: A Mixed Mode Study Protocol," BMC Public Health, vol. 20, no.787, pp. 1-6, 2020, doi: 10.1186/s12889-020-08910-3. 